\title{
Exploring the occurrence rate of PMSE-Es by Digisonde at Troms $\varnothing$
}

\author{
HaiLong Li1 ${ }^{*}$, ShuCan Ge1,2, Lin Meng ${ }^{1}$, MaoYan Wang ${ }^{3}$, Abdur Rauf', and Safi Ullah'1 \\ ${ }^{1 S}$ chool of Electronic Science and Engineering, University of Electronic Science and Technology of China, Chengdu 610054, China; \\ ${ }^{2}$ National Key Laboratory of Electromagnetic Environment, China Research Institute of Radiowave Propagation, Qingdao 266107, China; \\ ${ }^{3}$ School of Physics, University of Electronic Science and Technology of China, Chengdu 610054, China
}

Key Points:

- PMSE occur much more than PMSE-Es.

- The diurnal, day-to-day and year-to-year variations of PMSE-Es and PMSE are similar.

- The correlation between the year-to-year variation of PMSE OR and PMSE-Es OR is positive.

Citation: Li, H. L., Ge, S. C., Meng, L., Wang, M. Y., Rauf, A. and Ullah, S. (2021). Exploring the occurrence rate of PMSE-Es by Digisonde at Tromsø. Earth Planet. Phys., 5(2), 187-195. http://doi.org/10.26464/epp2021017

\begin{abstract}
Polar mesosphere summer echoes (PMSE) are observed simultaneously with Digisonde and EISCAT VHF radar. The phenomenon of irregular Es layers is called PMSE-like or PMSE-Es (Polar Mesosphere Summer Echoes-Es) and has some relationship with real PMSE. In this paper, the characteristics of irregular Es layers at 80-100 km were observed by Digisonde at Tromsø during 2003-2014 are statistically analyzed with ionograms. The diurnal, day-to-day and year-to-year variations and discrepancies of occurrence rate between PMSE and PMSE-Es are compared with the statistical results observed by Esrange MST radar (ESRAD), and the reasons are discussed. The results show that the trends in the occurrence rate of PMSE-Es are similar to the trends in the occurrence rate of PMSE, but there are some notable differences. The occurrence rate of PMSE-Es is much lower than the occurrence rate of PMSE. The minimum value of PMSE-Es appears 1-2 hours earlier than the minimum value of the PMSE occurrence rate, while PMSE-Es appear earlier than PMSE in the year. In addition, there is a significant positive correlation between the annual average occurrence rates of PMSE and PMSE-Es. PMSEEs is a relatively important occurrence in the polar mesopause. Analysis of its characteristics can provide new ideas and methods for studying the formation mechanism of PMSE.
\end{abstract}

Keywords: Polar mesosphere summer echoes; Digisonde; EISCAT VHF radar; PMSE-Es; Esrange MST radar

\section{Introduction}

Polar mesosphere summer echoes (PMSE) are abnormally strong radar echoes from altitudes of $80-90 \mathrm{~km}$ during local summer near the mesopause (Ecklund and Balsley, 1981). Since the first observation of PMSE, scientists have carried out comprehensive research and gained many insights and achievements at a variety of frequency bands ranging from MF/HF (Medium Frequency/High Frequency) (Karashtin et al., 1997; Ogawa et al., 2002, 2003, 2011, 2013; Hosokawa et al., 2004, 2005) to VHF and UHF bands (Cho et al., 1992; Li HL et al., 2010; Liu EX et al., 2012; Li and Rapp, 2013; Mann et al., 2016; Mahmoudian et al., 2018; Rauf et al., 2018, 2019; Ge SC et al., 2020, 2021). In recent years, new experiments were carried out based on in-situ observations, groundbased observations, numerical simulations, and theoretical considerations, revealing some possible scientific explanations for the generation of PMSE. Some key parameters, such as ion and electron temperature, electron density, dust density, and dust charge

Correspondence to: H. L. Li, hailong703@163.com

Received 25 OCT 2020; Accepted 04 JAN 2021.

Accepted article online 27 JAN 2021.

(C)2021 by Earth and Planetary Physics. were detected, useful measures for explaining the formation mechanism of PMSE. Though several theories have been developed for explaining PMSE, a conclusive explanation still has not been put forward.

PMSE exhibited pronounced day-to-day variations from the first observations for 1979-1980 (Ecklund and Balsley, 1981). In 1998, Kirkwood et al. studied the short-term variation characteristics of PMSE (Kirkwood et al., 1998), and a similar pattern of PMSE SNR (signal-to-noise ratio) daily variations were studied using the ALOMAR SOUSY radar during 1994-1997 (Hoffmann et al., 1999). Barabash et al. (2002) investigated the diurnal variations of PMSE observed with ESRAD (Esrange radar). Latteck et al. (2007) showed the characteristics of the PMSE occurrence rate (OR) using ALOMAR SOUSY radar observation data. The same year, Morris et al. (2007) reported similar semidiurnal variations of PMSE strength and OR for one season from 2004-2005 at Davis, Antarctica. Bremer et al. (2009) reported long-term observations of PMSE by ESRAD during 1999-2008, while Smirnova et al. (2010) studied the diurnal and the day-to-day variations of PMSE observed by ESRAD during 1997-2008. Latteck and Bremer (2013) reported longterm variations of PMSE for 17 years from 1994-2012. In 2007, Li et al. gave the long-term variations of polar mesosphere summer 
echoes-sporadic E (PMSE-Es) for eight years from 1995-2002, detected by Digisonde at Antarctica (Li HL et al., 2007a).

lonospheric sporadic E (Es) layers are thin-layered structures with intense, high electron densities at $80-130 \mathrm{~km}$ altitudes, and their appearance is usually due to particle sedimentation. The electron density in the polar Es layer is relatively high, and we found that the occurrence regions of some Es layers overlap with PMSE, with similar characteristics. We defined the phenomenon of irregular Es layers observed by Digisonde at $80-100 \mathrm{~km}$ as PMSE-like or PMSEEs (Polar Mesosphere Summer Echoes-sporadic E). It has close ties to real PMSE, although the formation mechanism of the Es layer at polar latitudes is still inconclusive and requires further verification. Further, researchers have done much-related work regarding the generation mechanism of PMSE. For example, a series of experiments were based on field observations of sounding rockets, ground observations of radars and lidars, and numerical simulations combined with microphysical models of aerosol particles. However, so far there is still no conclusive mechanism.

In this paper, the characteristics of the mesospheric radar echoes observed simultaneously with Digisonde and EISCAT VHF radar at Troms $\varnothing$ are analyzed first. Then, based on data obtained from 2003 to 2014 by Digisonde at Tromsø, the diurnal, day-to-day and year-to-year variations of PMSE-Es OR are studied and are compared with the statistical results of PMSE OR observed by ESRAD. At the end, the main differences in their characteristics and possible reasons are given.

\section{Experiments Configuration}

PMSE can be easily observed by the monostatic EISCAT VHF radar at Tromsø, Norway $\left(69.6^{\circ} \mathrm{N}, 19.2^{\circ} \mathrm{E}\right)$. It operates in the $224 \mathrm{MHz}$ band with a peak transmitter power of $2 \times 1.5 \mathrm{MW}$ using a $120 \mathrm{~m} \times$ $40 \mathrm{~m}$ parabolic cylinder antenna. The ionogram is a record of ionospheric conditions, indicated by the relationship between the frequency of the radio pulse emitted upward and the virtual altitude of echoes reflected from the ionosphere. Figure 1 shows the PMSE observed by EISCAT VHF (224 MHz) radar during 09:00-10:00 on July 12,2007 . At the same time and site, echoes in the mesopause were observed by Digisonde at 09:45 UT on July 12, 2007. The ionogram is shown in Figure 2. The data are commonly recorded once every quarter of an hour, with the $x$-axis and $y$-axis representing frequency $(\mathrm{MHz})$ and virtual altitude $(\mathrm{km})$, respectively. The main parameters of the Digisonde and EISCAT VHF radars are collected in Table 1 (Rietveld et al., 2008). The local time (LT) at Troms $\varnothing$ is 1 hour ahead of universal time (LT = UT+1 hr).

Figure 1 shows an obvious PMSE event at an altitude of 80-90 km. The Digisonde ionogram in Figure 2 at 09:45 UT on July 12, 2007 also shows an obvious Es-like trace at an altitude of $80-100 \mathrm{~km}$. For a detailed description of the ionogram trace, please refer to Rietveld et al. (2008) observed by Digisonde while PMSE is detected by EISCAT VHF radar. However, this phenomenon observed by Digisonde may not be a PMSE as generally considered, suggesting that PMSE-Es instead may have appeared at this time.

\section{Criteria of PMSE-Es Observed by Digisonde}

Li HL et al. (2007b) found Es traces by analyzing the ionogram observed at Zhongshan Station, Antarctica $\left(69.4^{\circ} \mathrm{S}, 76.4^{\circ} \mathrm{E}\right)$. These were similar to PMSE, the so-called PMSE-Es, and Li HL et al. $(2007 a, b)$ also described a method to determine PMSE-Es.

In order to explore whether there exists a PMSE-Es similar to the southern hemisphere in the northern hemisphere, the ionogram

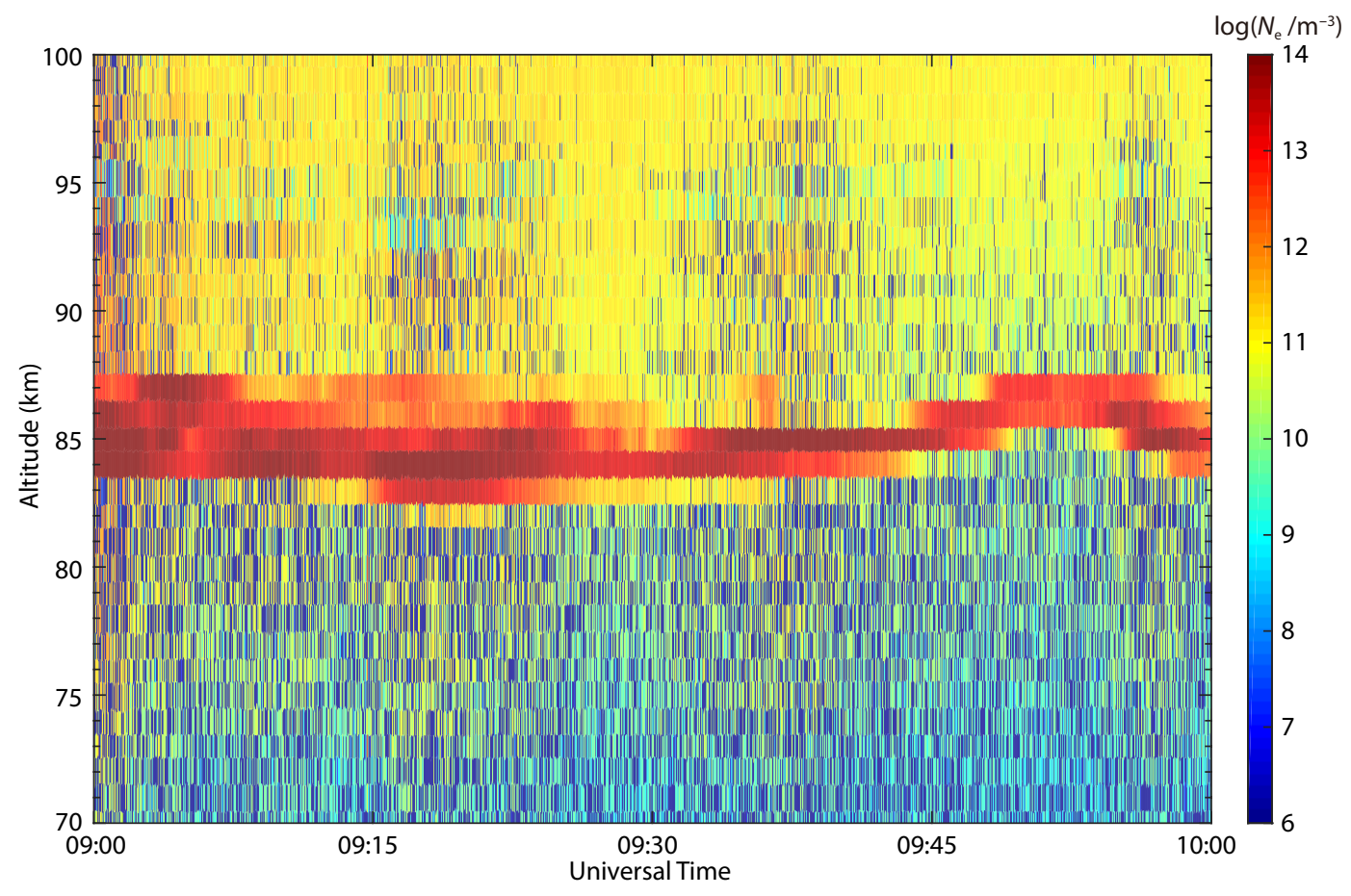

Figure 1. PMSE was observed by EISCAT VHF radar during 9:00-10:00 UT on July 12, 2007. 


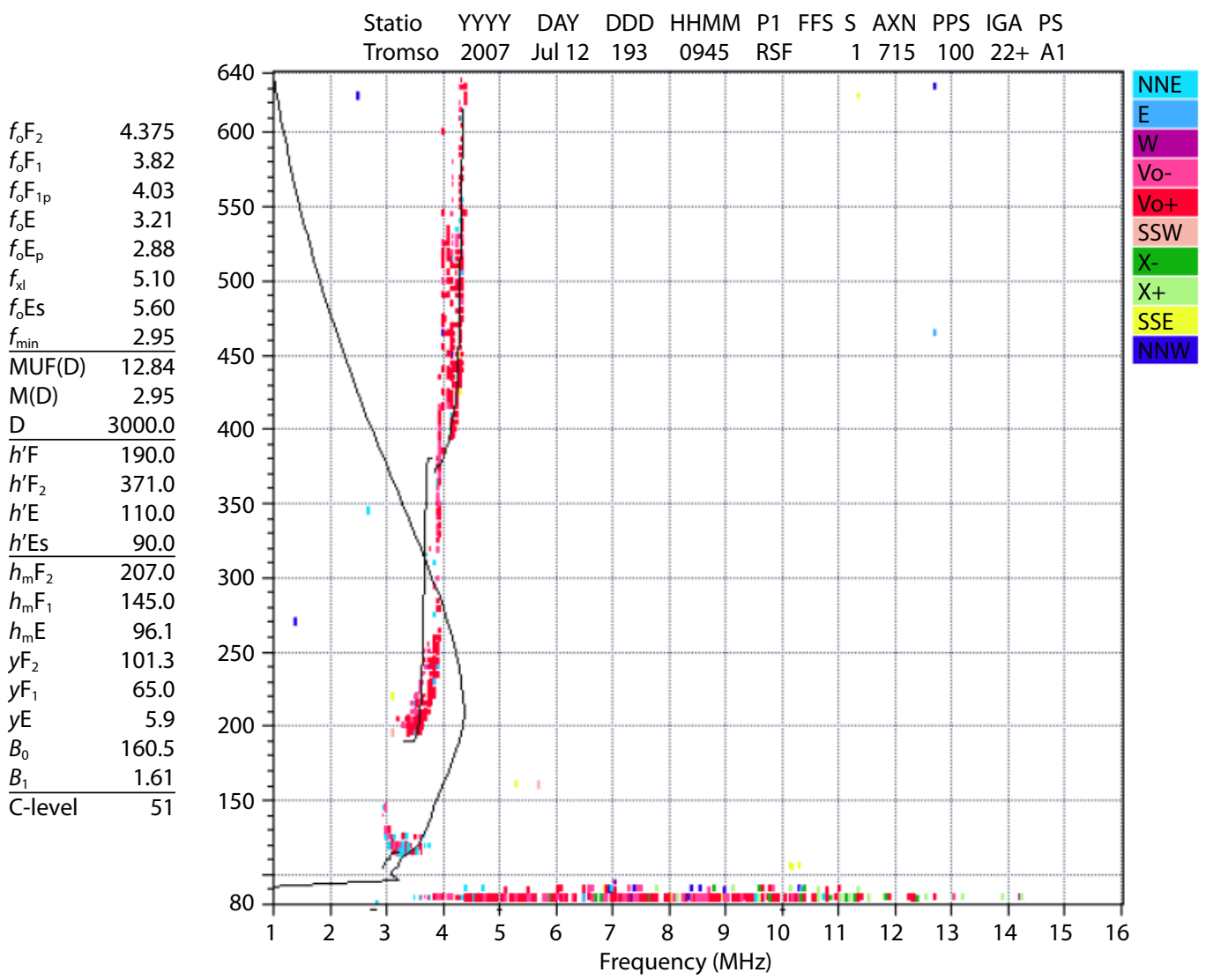

Figure 2. Digisonde ionogram at 09:45 UT on 12 July, 2007.

Table 1. Digisonde instrument and EISCAT VHF radar characteristics.

\begin{tabular}{lcc}
\hline \multicolumn{1}{c}{ Name } & Lowell Digisonde instrument & EISCAT VHF radar \\
\hline Location & Ramfjordmoen, $69.6^{\circ} \mathrm{N}, 19.2^{\circ} \mathrm{E}$ & Ramfjordmoen, $69.6^{\circ} \mathrm{N}, 19.2^{\circ} \mathrm{E}$ \\
Antenna type & Rhombic & Parabolic cylinder \\
Pulse repetition frequency & $200 \mathrm{~Hz}$ & - \\
Beam width & - & $1.2^{\circ} \times 1.6^{\circ}$ \\
Peak power (normal operation) & $300 \mathrm{~W}$ & $3 \mathrm{MW}$ \\
Range resolution & $0.5 \mathrm{~km}$ & $0.3 \mathrm{~km}$ \\
Time resolution & - & $5 \mathrm{~s}$ \\
Frequency coverage & Typically $1-12.0 \mathrm{MHz}$, but programmable & $224 \mathrm{MHz}$ \\
Frequency resolution & $50 \mathrm{kHz}$ & - \\
Sweep time (typical frequency range) & $5-6 \mathrm{~min}$ & - \\
Common ionograms sample interval & $15 \mathrm{~min}$ & - \\
\hline
\end{tabular}

observed by Digisonde at the Tromsø was used to compare and verify this hypothesis. Figures 3 and 4 show the monthly median value of the Es virtual altitude as a function of time in January and July 2009 and 2013, respectively. The black and blue lines represent the monthly median value of the Es virtual altitude in January and July, respectively. In Figures 3 and 4, the monthly median value of the Es virtual altitude could occur below $100 \mathrm{~km}$, and the height is lower in July and higher in January. The altitude and season of the irregular Es layers occurrence are consistent with PMSE observed in the northern hemisphere (Liu JY et al., 2002). The Es- like trace agrees well with the PMSE-Es criteria given by Li HL et al. (2007b). Therefore, PMSE-Es exists in the mesopause of the northern hemisphere in summer.

\section{Characteristics of PMSE-Es at Tromsø}

The PMSE-Es has its own regular variation rules, such as diurnal variation and day-to-day variation, etc. (Barabash et al., 2002; Smirnova et al., 2010). We mainly studied the characteristics of PMSE-Es, to provide a basis for the comparative study of PMSE 


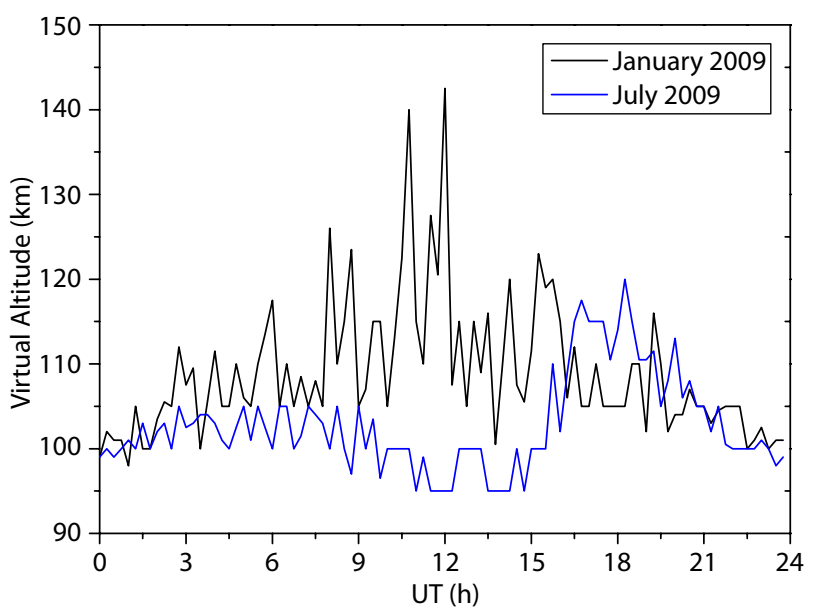

Figure 3. The monthly median value of Es virtual altitude as a function of time in January and July 2009.

and PMSE-Es OR in the next section.

\subsection{Diurnal Variations}

The investigation of the OR of irregular Es layer is carried out on the basis of data recorded at fifteen minutes intervals by Digisonde from 2003 to 2014. According to these ionograms, the ratio of time when PMSE-Es exists to the corresponding total observational time is expressed as the occurrence rate of PMSE-Es.

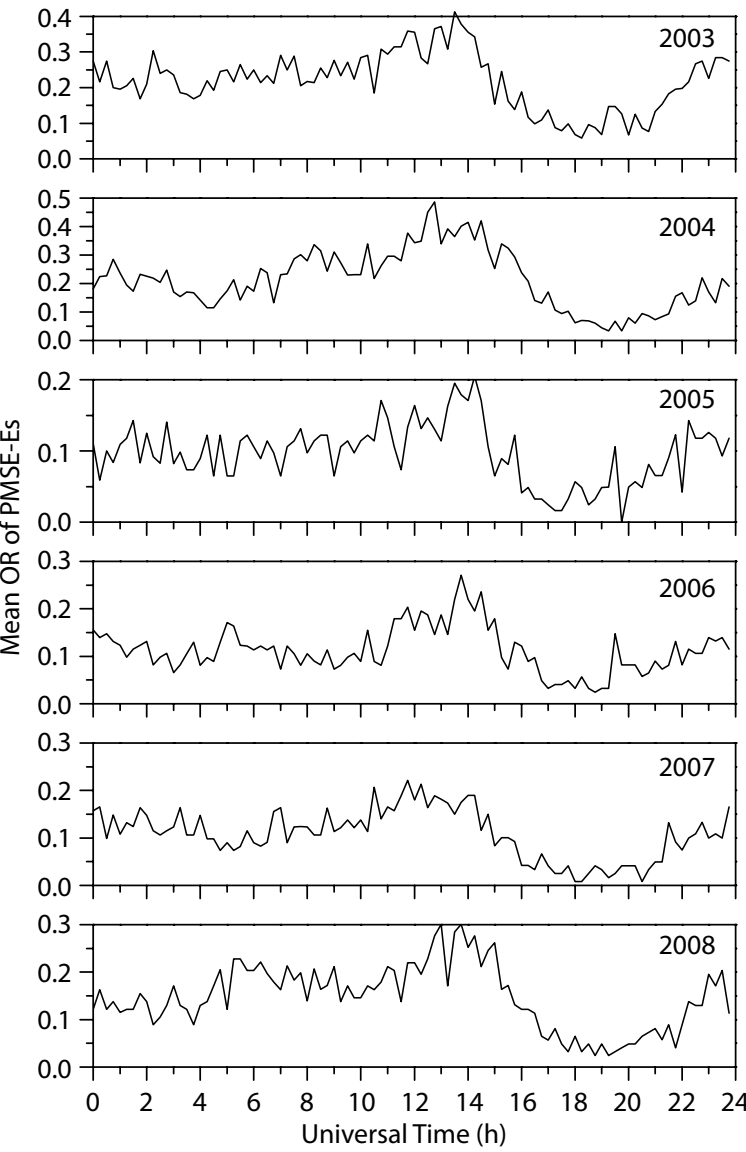

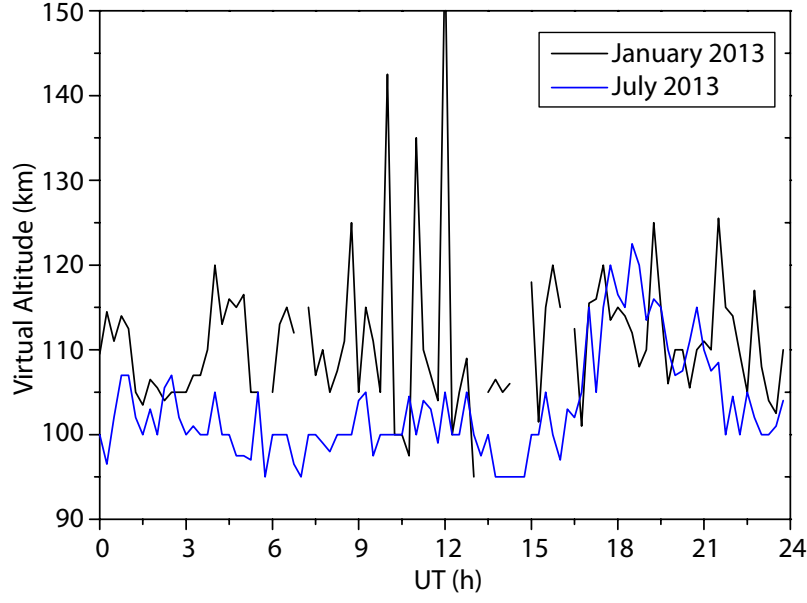

Figure 4. Same plot as in Figure 3, but for the periods of January and July 2013.

The PMSE-Es OR based on four months of data (from May to August) from 2003 to 2014 are given in Figure 5. The $x$-axis and $y$-axis represent universal time (UT) and mean OR of PMSE-Es over the four month period (from May to August), respectively. In order to better distinguish characteristics of PMSE-Es, nine nonlinear curves are used to analyze the relationship between PMSE-Es OR and time in each subgraph. According to the ionogram, we define the PMSE-Es OR equal to total PMSE-Es occurrence time divided by total observation time. Analyzing Figure 5, the PMSE-Es OR
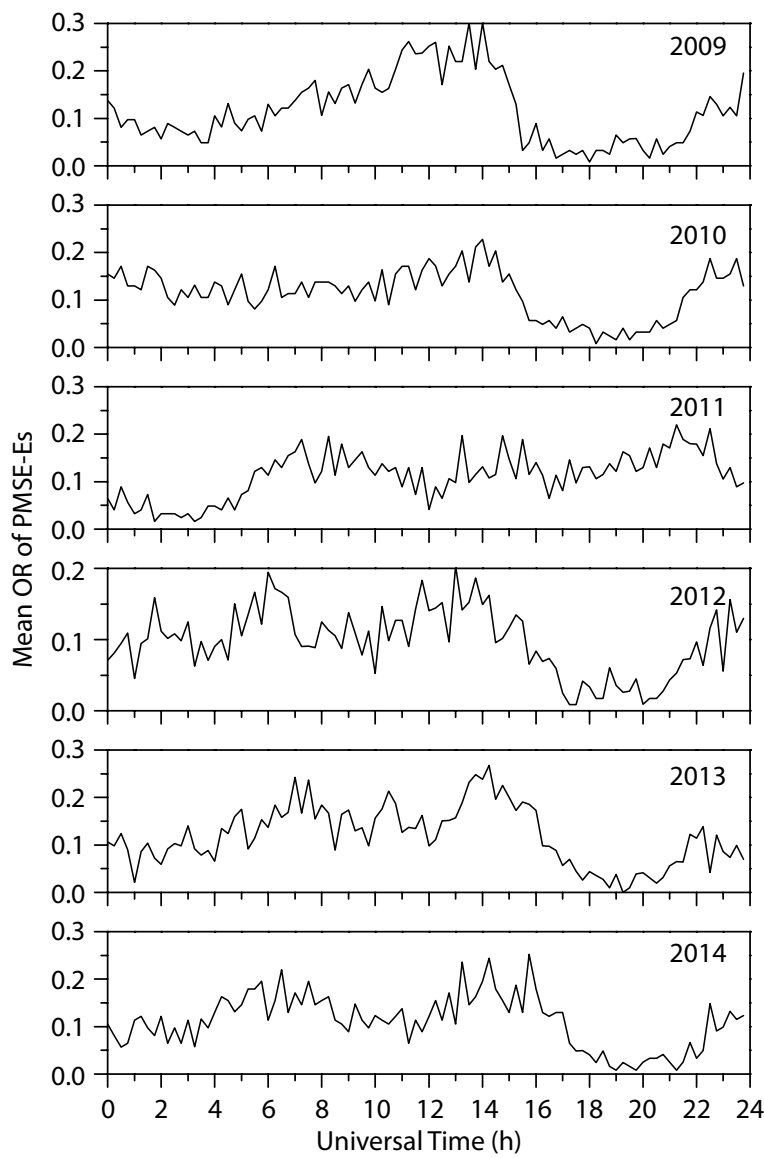

Figure 5. Diurnal variations of mean PMSE-Es occurrence rate (OR) during 2003-2014. 
shows obvious diurnal characteristics with a peak value at 12-15 UT and a minimum value at 17-22 UT, except for 2011, which has a peak value at 7-23 UT and a minimum value at 1-4 UT. In 2008, 2012, 2013 and 2014, the PMSE-Es OR has two peaks, and its second peak appeared at 4-8 UT. The minimum value that occurs in the evening is the minimum PMSE-Es OR in a year, except in 2011. By our calculations, the PMSE-Es OR shows lower levels from 2003 to 2014. The maximum PMSE-Es OR is about $20 \%-40 \%$, and the minimum value is about $0.02 \%$, which indicates that the duration of PMSE-Es is relatively short. Liou et al. (1997) indicated that auroral intensities maximize in the post-noon LT sector, and sometimes exhibit a weaker local maximum emission in the night sector. The diurnal variation of PMSE-Es is consistent with these observations (Liou et al., 1997), and thus we can posit what may cause the diurnal variation of PMSE-Es. The latitude of the Troms $\varnothing$ station is about $69.65^{\circ} \mathrm{N}$, which is located outside the aurora oval throughout the day and exhibits a relatively high occurrence rate of PMSE-Es. When the Tromsø station is covered by the auroral oval region, the occurrence rate of PMSE-Es drops sharply due to the influence of auroral particles. When it left from the aurora oval, the occurrence rate of PMSE-Es began to rise again.

\subsection{Day-to-Day Variations of PMSE-Es}

Figure 6 describes the day-to-day variation of PMSE-Es OR which is calculated in units of 5 days of ionogram data (PMSE-Es OR is the average of 5 days of measurement data) detected by Digisonde from 2003 to 2014. Note that in Figure 6 the first bar shows

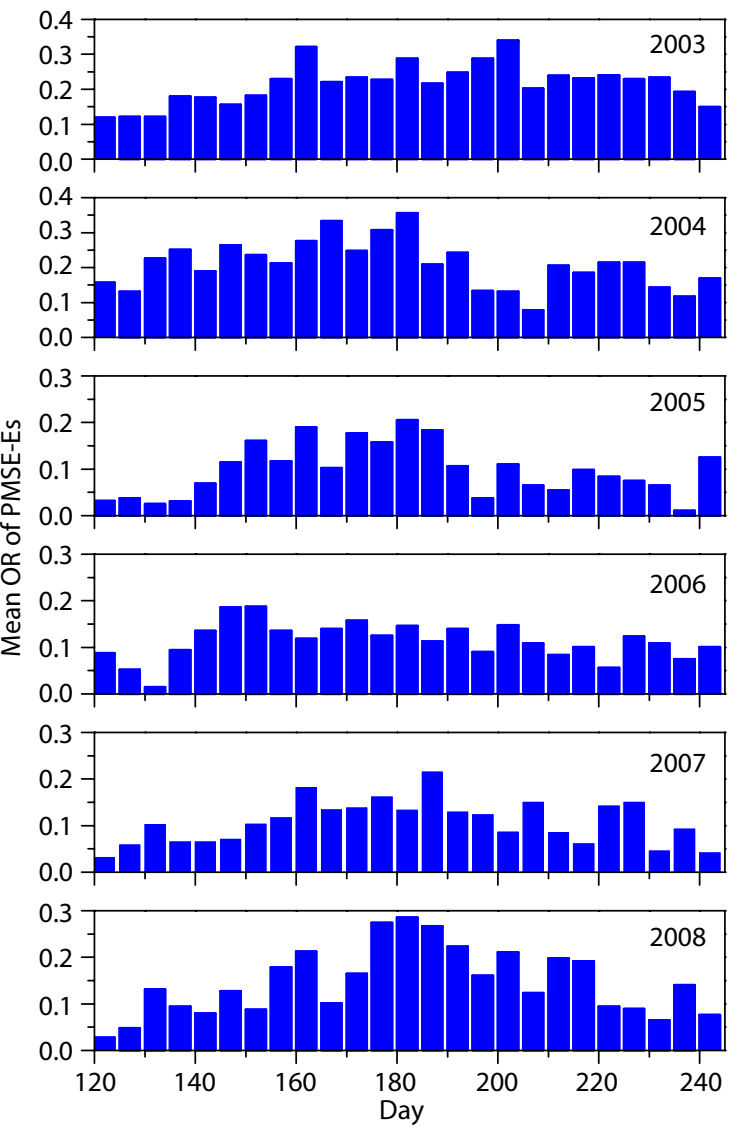

the average PMSE-Es OR on the 121-125th day of the year for 2004, 2008 and 2012, while the first bar for other years uses the average of the PMSE-Es OR on days 122-126.

Since the PMSE-Es OR is extremely low during the year except for May to August, only four months of data from May to August is given in Figure 6. The $x$-axis and $y$-axis represent days (every five days equals one unit) and PMSE-Es OR, respectively. Generally, the PMSE-Es OR begins to increase from the end of April or the beginning of May, reaches the maximum in July, and finally drops in August. This tendency was found in all of the years studied, with the exception of 2012 when one broad minimum was observed at days 190-220. The comparative analysis found that the day-today variation of PMSE-Es OR is consistent with the day-to-day variation of PMSE OR (Smirnova et al., 2010); these results are presented in Section 5.2 .

\section{Comparison of Observed Characteristics Between PMSE-Es and PMSE}

Giving the experimental observation of 8:00-11:00 UT on July 12, 2007 (VHF radar observation time is 8:00-10:47 UT) as an example, data from the EISCAT UHF and VHF radars and the corresponding time ionogram data are used make a comparative analysis. Figures 7 and 8 describe the PMSE observed by EISCAT UHF and VHF radars on July 12, 2007, respectively. Figure 9 is the ionogram observed by the Digisonde during the corresponding time period.
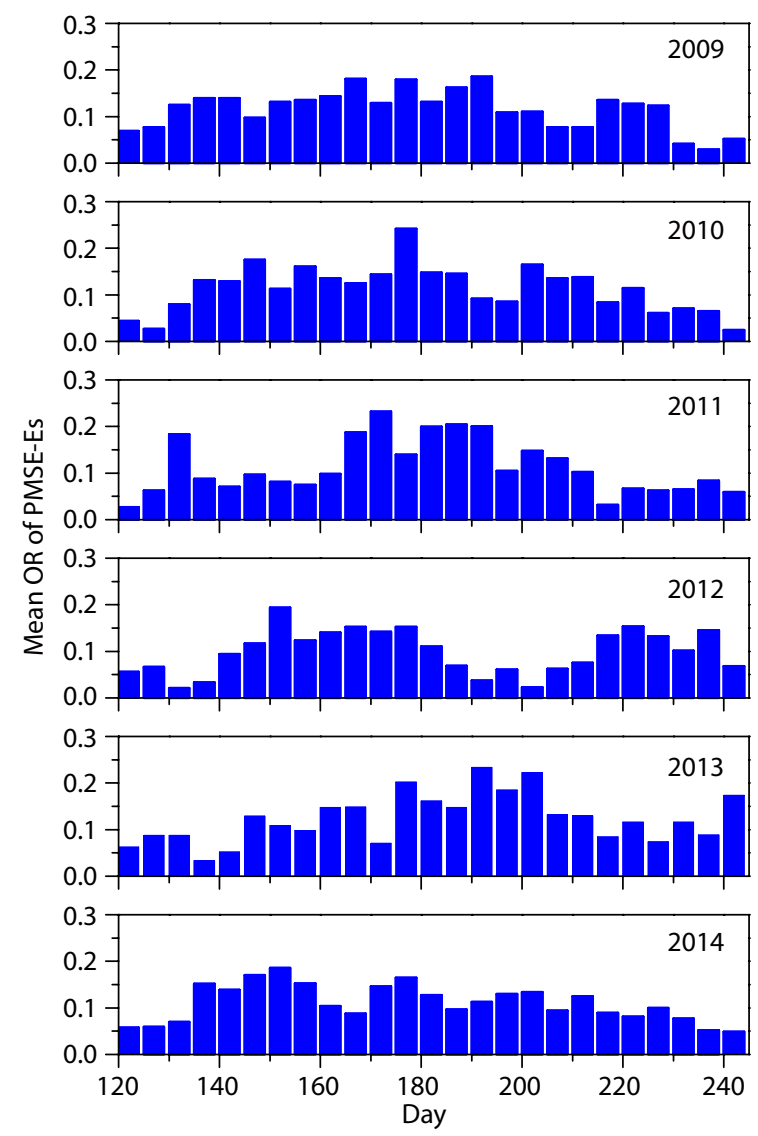

Figure 6. Day-to-day variation of the PMSE-Es OR during 2003-2014. 


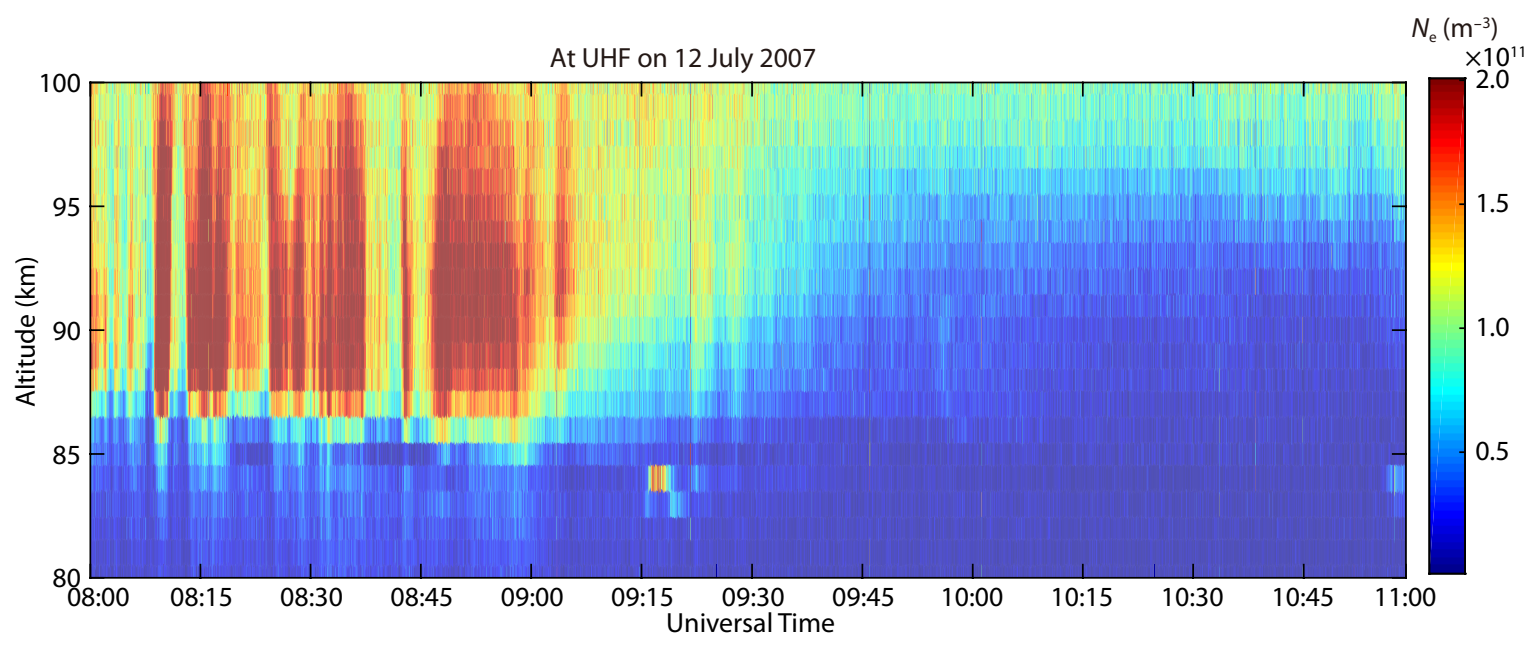

Figure 7. PMSE observed by EISCAT UHF radar during 8:00-11:00 UT on July 12, 2007.

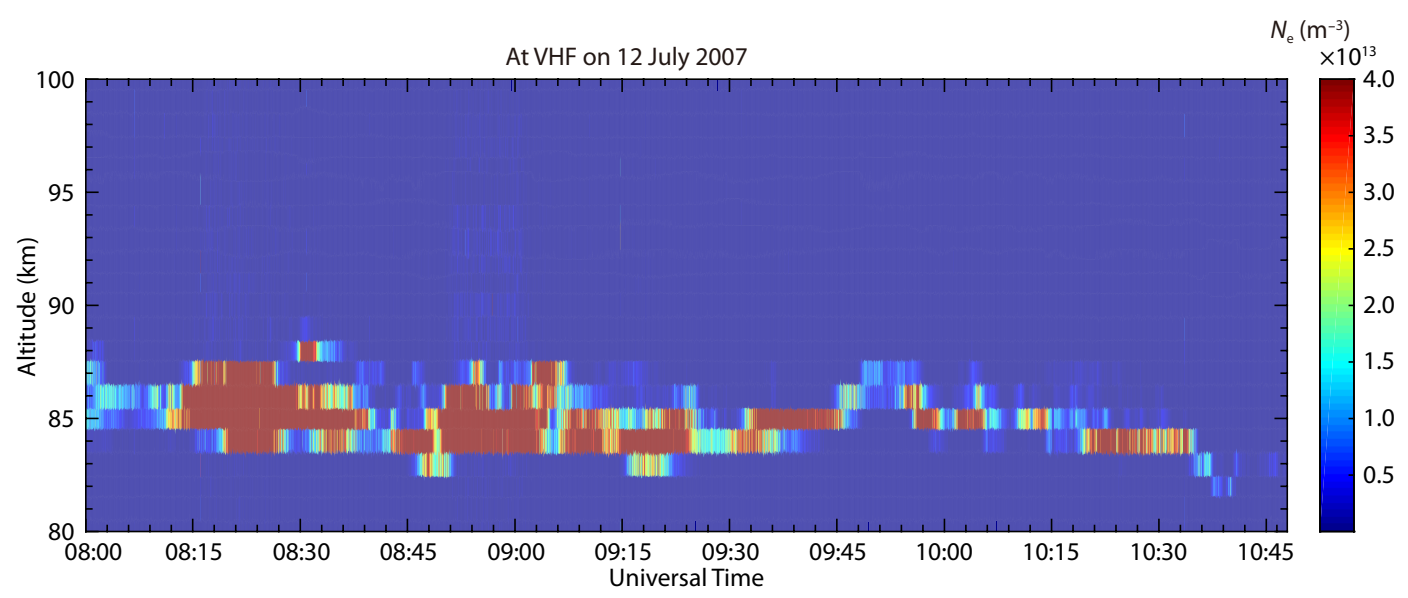

Figure 8. PMSE observed by EISCAT VHF radar during 8:00-10:47 UT on July 12, 2007.

As time progresses, the corresponding maximum plasma frequency becomes smaller during the trace of the ionogram. Simultaneously, the plasma frequency range is reduced and dispersed, indicating that the echo density is weakening. This is not consistent with the intensity of PMSE at the corresponding time but is consistent with the intensity of the high energy particle precipitation observed by EISCAT UHF radar in Figure 7. Thus, as time goes by, the intensity of the high energy particle precipitation at the UHF becomes weaker, and its range becomes smaller. As shown in Figure 9, the trace of the ionogram is very sparse at 10:45 UT, i.e., few weak PMSE-Es appear, but there is a strong PMSE-Es during the rest of the time. This is consistent with the PMSE intensity observed by the EISCAT VHF radar.

\section{Comparing Diurnal, Day-to-Day and Year-to-Year Variations of PMSE-Es with PMSE}

PMSE-Es detected by Digisonde at Troms $\varnothing$ and PMSE observed by the Esrange MST $52 \mathrm{MHz}$ radar (ESRAD) $\left(67.88^{\circ} \mathrm{N}, 21.10^{\circ} \mathrm{E} . \mathrm{LT}=\right.$ $\mathrm{UT}+1 \mathrm{hr}$ ) are used to conduct a comparative analysis. Their characteristics are similar, such as diurnal and seasonal trends, but there are still some differences, the most obvious being that the PMSE
OR is much higher than that of PMSE-Es. Some smaller differences at multi-scales are discussed below.

\subsection{Diurnal Variation}

In 2010, Smirnova et al. (2010) used ESRAD observation data from 1997 to 2008 to analyze the diurnal variations of PMSE OR and discussed the influence of equatorial meridional wind/zonal wind shear, geomagnetic activity, solar activity, and cosmic noise absorption on PMSE. Here, we use ESRAD observation data from June 1 to August 5 of each year from 1997 to 2008 to analyze the diurnal variation of PMSE.

The diurnal variation of PMSE OR has dominating day-night and semidiurnal variations with one maximum at 12-15 UT and one minimum at 19-23 UT, which are stable through the whole season. At the same time, there is one secondary maximum at 3-6 UT and minimum at about 6-10 UT, which begins to decrease rapidly at 15-17 UT. However, because of irregular forms, diurnal variations can reveal several weak maxima and minima before the deep decrease, which starts at about 15-17 UT. As mentioned above, the PMSE-Es OR appear to peak and nadir at 12-16 UT and 17-22 UT, respectively. The maxima of PMSE and PMSE-Es OR are 

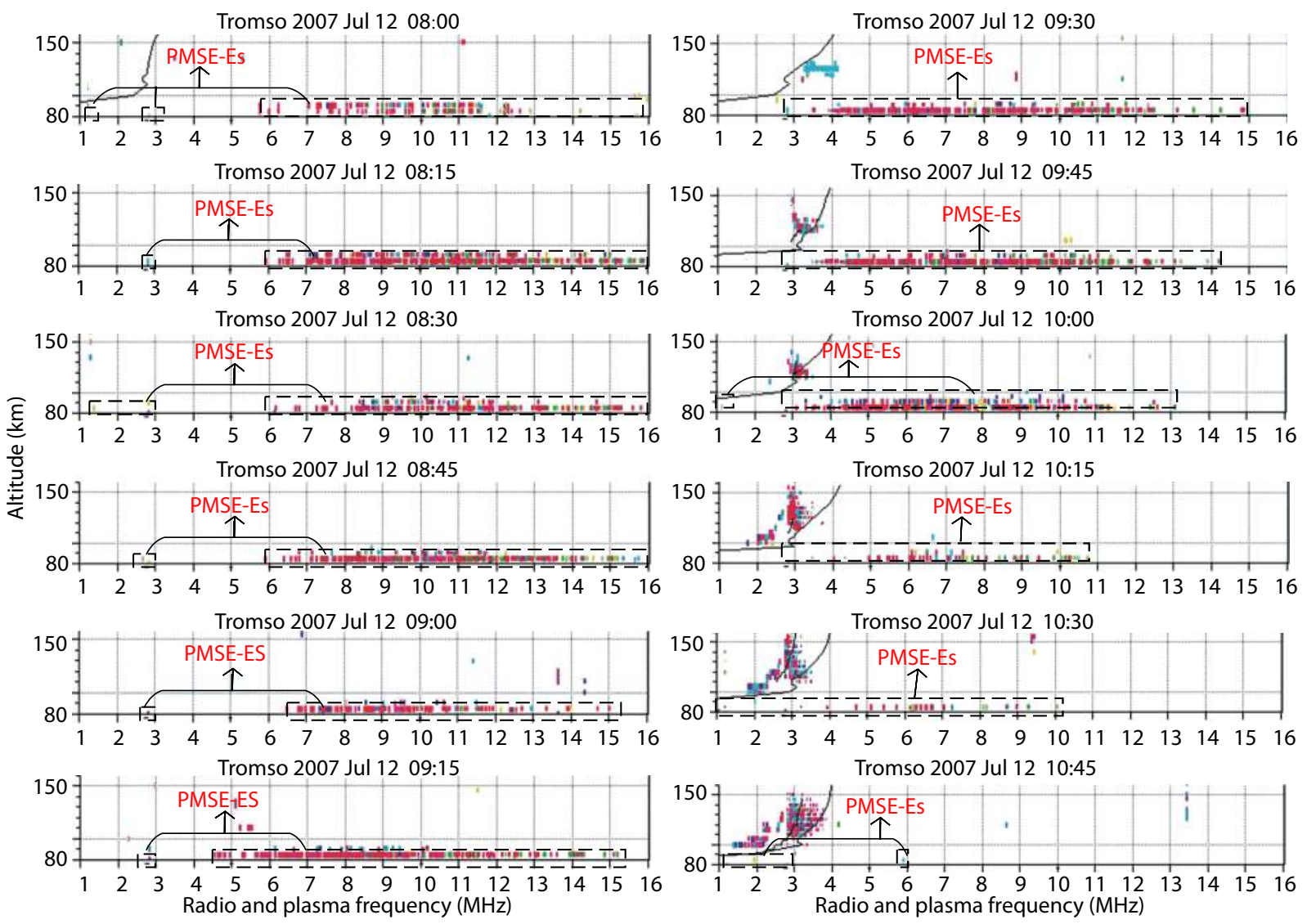

Figure 9. Digisonde ionogram during 8:00-11:00 UT on July 12, 2007.

consistent. The minimum of PMSE-Es occurs about 1 hour in advance, but the timing before the deep decrease which starts at about 15-17 UT is consistent. The secondary maximum only occurs in the early morning at 4-8 UT in several years.

\subsection{Day-to-Day Variation}

The average estimated time for the start of the PMSE is 21-22 May, and the average time for the end of PMSE season is 19-20 August (Smirnova et al., 2010). PMSE usually start in the last ten days of May, increase sharply until the beginning of June, stay at the highest level with OR reaching $90 \%$ in July, then decrease gradually until the end of August every year. These observations are in general agreement with independent observations from different radars located at similar geographical latitudes (Balsley and Huaman, 1997; Kirkwood et al., 1998).

Though the day-to-day variation rule of PMSE-Es OR has extremely similar characteristics with that of PMSE, we found that they occur throughout the four month period of May to August. These differences can be explained by the following two aspects:

First, the minor deviation is unavoidable because the PMSE-Es criteria come from the virtual altitude and scanned ionogram trace observed by Digsionde without the support of strong echoes. Second, the data used in the paper is extracted from ionograms, with time resolution lower than that in VHF radar, which can continuously observe PMSE with higher time resolution. PMSE-Es was affected by many elements, such as precipitating particles, atmospheric temperature, and general atmospheric circulation. In addi- tion, the measurement results were different due to the dispersion medium properties of the ionosphere, while the diffusion characteristics of the ionosphere vary with the operating frequency (Bremer et al., 1996).

\subsection{Year-to-Year Variation}

The year-to-year variations of the PMSE OR observed by ESRAD and PMSE-Es observed by Digisonde were both averaged over the time interval of May 1 to August 31 for the years 2003-2014, shown in Figure 10 . The $x$-axis represents years, while left and right $y$-axis represents the mean PMSE OR (black curve) and mean PMSE-Es OR (blue curve), respectively. Figure 10 illustrates the PMSE and PMSE-Es OR both averaged. This OR is lower than that given by Smirnova et al. (2010) because the time period used to calculate the average PMSE OR is different; they used the average PMSE OR from June 1 to July 31 for analysis, and the PMSE OR is usually lower in May and August. However, the variation trend is highly consistent, especially in 2003, 2007, 2008 and 2011. In addition, we used the correlation coefficient method to analyze the correlation between the average PMSE OR and PMSE-Es OR, and the correlation coefficient $R=0.71$, which shows that they have a significant positive correlation.

Still, the results about PMSE year-to-year variations are controversial. Smirnova et al. (2010) found a negative correlation between the year-to-year variations of PMSE and solar activity, and a positive correlation between long-term PMSE variations observed by ESRAD and geomagnetic activity (Smirnova et al., 2010). Bremer et 


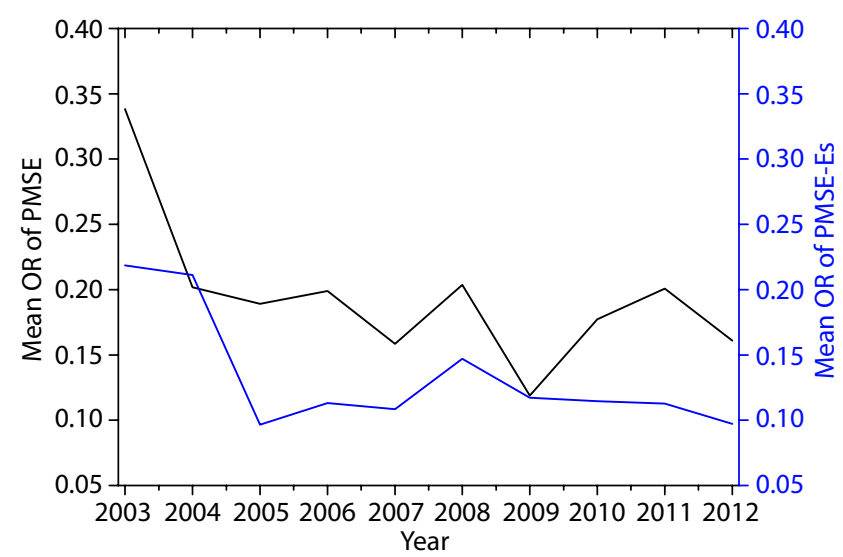

Figure 10. Year-to-year mean OR of PMSE and PMSE-Es during the years 2003-2012.

al. found that PMSE echoes observed at Andenes are positively correlated with both solar and geomagnetic activity (Bremer et al., 2009). Thus the year-to-year variations of PMSE-Es with solar and geomagnetic activity are a controversial and very complex issue, which needs more in-depth exploration and future research. Recently, Hall et al. (2020) reported that the meteor radar located at Svalbard, Norway $\left(78.2^{\circ} \mathrm{N} 15.1^{\circ} \mathrm{E}\right)$ is capable of detecting PMSE. In a subsequent study, we will conduct a comparison of PMSE observed by the meteor radars at Svalbard and Tromsø co-located with EISCAT VHF radar (see examples in Hall et al., 2006; Yi W et al., 2019), which may help us to understand the physical processes of these crucial phenomena.

\section{Conclusions}

This paper studied the irregular echoes from the polar summer mesopause observed simultaneously with Digisonde and EISCAT VHF radar. The unique long-term data extracted from Digisonde ionograms at Tromsø from 2003 to 2014 was used to study the characteristics of PMSE-Es. We compared the diurnal, day-to-day and year-to-year variations of PMSE OR and PMSE-Es OR, and obtained the following conclusions:

(1) The OR of PMSE is much higher than that of PMSE-Es.

(2) The diurnal, day-to-day and year-to-year variations of PMSE-Es OR and PMSE OR are similar. Nevertheless, there are also differences.

1) Diurnal variation: The maximal value of PMSE OR appears at 12-15 UT, and the minimal value appears at 19-23 UT. At the same time, there is a second maximal value at 3-6 UT and second minimal value at 6-10 UT. The maximal value of PMSE-Es OR appeared at 12-16 UT, and minimal values appeared at 17-22 UT. The minimal value of PMSE-Es appeared 1-2 hours earlier than that of PMSE, and the second maximal value of PMSE-Es sometimes appears at 4-8 UT.

2) Day-to-day variation: PMSE usually begins to appear at the end of May, and increases rapidly at the beginning of June, remains high in July, then gradually decreases or disappears at the end of August. PMSE-Es have obvious day-to-day variations which appear from May to August, and it appears earlier than PMSE every year.

3) Year-to-year variation: There is a significant positive correlation between the year-to-year variation of PMSE OR and PMSE-Es OR.

These results show that PMSE-Es events may become important phenomena in the polar mesosphere, and we present a novel method to analyze PMSE.

\section{Acknowledgments}

This work is supported by the National Natural Science Foundation of China (No. 61671116, 61771096, 11905026), National Key Research and Development Program of China (No.2019YFA 0210202) and Fundamental Research Funds for the Central Universities (No. ZYGX2019Z006, ZYGX2019J012). We are deeply grateful to Chris Hall from the Arctic University of Norway for providing the Tromsø Digisonde ionogram data. The authors thank Sheila Kirkwood at the Swedish Institute of Space Physics for providing ESRAD data and for hosting a study visit by Hailong Li. The EISCAT scientific association is supported by China (China Research Institute of Radiowave Propagation), Finland (Suomen Akatemia of Finland), Japan (the National Institute of Polar Research of Japan and Institute for Space-Earth Environmental Research at Nagoya University), Norway (Norges Forkningsrad of Norway), Sweden (the Swedish Research Council), and the UK (the Natural Environment Research Council).

\section{Availability of data and materials:}

http://www2.irf.se/program/paf/mst/?link=Data http://www.tgo.uit.no/ionodata/index.html

\section{References}

Balsley, B. B., and Huaman, M. (1997). On the relationship between seasonal occurrence of northern hemispheric polar mesosphere summer echoes and mean mesopause temperatures. J. Geophys. Res., 102(D2), 2021-2024. https://doi.org/10.1029/96JD01243

Barabash, V., Kirkwood, S., and Chilson, P. B. (2002). Are variations in PMSE intensity affected by energetic particle precipitation? . Ann. Geophys., 20(4), 539-545. https://doi.org/10.5194/angeo-20-539-2002

Bremer, J., Hoffmann, P., Manson, A., Meek, C. E., Rüster, R., and Singer, W. (1996). PMSE observations at three different frequencies in northern Europe during summer 1994. Ann. Geophys., 14(12), 1317-1327. https://doi.org/10.1007/s00585-996-1317-7

Bremer, J., Hoffmann, P., Latteck, R., Singer, W., and Zecha, M. (2009). Long-term changes of (polar) mesosphere summer echoes. J. Atmos. Solar-Terr. Phys., 71(14-15), 1571-1576. https://doi.org/10.1016/j.jastp.2009.03.010

Cho, J. Y. N., Kelley, M. C., and Heinselman, C. J. (1992). Enhancement of Thomson scatter by charged aerosols in the polar mesosphere: Measurements with a 1.29-GHz radar. Geophys. Res. Lett., 19(11), 1097-1100. https://doi.org/10.1029/92GL01155

Ecklund, W. L., and Balsley, B. B. (1981). Long-term observations of the Arctic mesosphere with the MST radar at Poker Flat, Alaska. J. Geophys. Res., 86(A9), 7775-7780. https://doi.org/10.1029/JA086iA09p07775

Ge, S. C., Li, H. L., Meng, L., Wang, M. Y., Xu, T., Ullah, S., Rauf, A., and Abdel, H. (2020). On the radar frequency dependence of polar mesosphere summer echoes. Earth Planet. Phys., 4(6), 571-578. https://doi.org/10.26464/epp2020061

Ge, S. C., Li, H. L., Xu, B., Xu, T., Meng, L., Wang, M. Y., Hannachi, A., Zhu, M. Y., Broman, L., Ullah, S., and Rauf, A. (2021). Characteristic analysis of layered PMSEs measured with different elevation angles at VHF based on an experimental case. Earth Planet. Phys., 5(1), 42-51. https://doi.org/10.26464/epp2021001

Hall, C., Adami, C., and Tsutsumi, M. (2020). First observations of Polar 
Mesospheric Echoes at both $31 \mathrm{MHz}$ and $53.5 \mathrm{MHz}$ over Svalbard $\left(78.2^{\circ} \mathrm{N}\right.$ 15.1 ${ }^{\circ}$ E). Exp. Results, 1, e44. https://doi.org/10.1017/exp.2020.51

Hall, C. M., Aso, T., Tsutsumi, M., Höffner, J., Sigernes, F., and Holdsworth, D. A. (2006). Neutral air temperatures at $90 \mathrm{~km}$ and $70^{\circ} \mathrm{N}$ and $78^{\circ} \mathrm{N}$. J. Geophys. Res., 111(D14), D14105. https://doi.org/10.1029/2005JD006794

Hoffmann, P., Singer, W., and Bremer, J. (1999). Mean seasonal and diurnal variations of PMSE and winds from 4 years of radar observations at ALOMAR. Geophys. Res. Lett., 26(11), 1525-1528. https://doi.org/10.1029/1999GL900279

Hosokawa, K., Ogawa, T., Yukimatu, A. S., Sato, N., and lyemori, T. (2004). Statistics of antarctic mesospheric echoes observed with the SuperDARN Syowa radar. Geophys. Res. Lett., 31(2), L02106. https://doi.org/10.1029/2003GL018776

Hosokawa, K., Ogawa, T., Arnold, N. F., Lester, M., Sato, N., and Yukimatu, A. S. (2005). Extraction of polar mesosphere summer echoes from SuperDARN data. Geophys. Res. Lett., 32(12), L12801. https://doi.org/10.1029/2005GL022788

Karashtin, A. N., Shlyugaev, Y. V., Abramov, V. I., Belov, I. F., Berezin, I. V., Bychkov, V. V., Eryshev, E. B., and Komrakov, G. P. (1997). First HF radar measurements of summer mesopause echoes at SURA. Ann. Geophys., 15(7), 935-941. https://doi.org/10.1007/s00585-997-0935-z

Kirkwood, S., Barabash, V., Chilson, P., Réchou, A., Stebel, K., Espy, P., Witt, G., and Stegman, J. (1998). The 1997 pmse season-its relation to wind, temperature and water vapour. Geophys. Res. Lett., 25(11), 1867-1870. https://doi.org/10.1029/98GL01243

Latteck, R., Singer, W., Morris, R. J., Holdsworth, D. A., and Murphy, D. J. (2007). Observation of polar mesosphere summer echoes with calibrated VHF radars at $69^{\circ}$ in the northern and southern hemispheres. Geophys. Res. Lett., 34(14), L14805. https://doi.org/10.1029/2007GL030032

Latteck, R., and Bremer, J. (2013). Long-term changes of polar mesosphere summer echoes at $69^{\circ} \mathrm{N}$. J. Geophys. Res., $118(18), 10441-10448$. https://doi.org/10.1002/jgrd.50787

Li, H. L., Wu, J., Liu, R. Y., and Huang, J. Y. (2007a). Study on mesosphere summer echoes observed by digital ionosonde at Zhongshan Station, Antarctica. Earth Planets Space, 59(10), 1135-1139. https://doi.org/10.1186/BF03352056

Li, H. L., Wu, J., Liu, R. Y., and Huang, J. Y. (2007b). The statistics analysis of mesosphere summer echoes observed by DPS-4 at Zhongshan station, Antarctica. Chin. J. Polar Res. (in Chinese), 19(1), 1-9.

Li, H. L., Wang, M. Y., Wu, J., Wu, J., Xu, B., and Huang, J. Y. (2010). Preliminary experiment analysis about PMSE artificial electron heating and overshoot. Chin J. Geophys. (in Chinese), 53(12), 2836-2842. https://doi.org/10.3969/j.issn.0001-5733.2010.12.006

Li, Q., and Rapp, M. (2013). PMSE observations with the EISCAT VHF- and UHFradars: ice particles and their effect on ambient electron densities. J. Atmos. Solar-Terr. Phys., 104, 270-276. https://doi.org/10.1016/j.jastp.2012.10.015

Liou, K., Newell, P. T., Meng, C. I., Brittnacher, M., and Parks, G. (1997). Synoptic auroral distribution: a survey using polar ultraviolet imagery. J. Geophys. Res., 102(A12), 27197-27205. https://doi.org/10.1029/97JA02638

Liu, E. X., Hu, H. Q., Liu, R. Y., Wu, Z. S., Wu, M. J., Yang, H. G., and Zhang, B. C. (2012). Diurnal variation of the HF radar echoes at Zhongshan Station and the influence of geomagnetic activity. Chin. J. Geophys. (in Chinese), 55(9),
3066-3076. https://doi.org/10.6038/j.issn.0001-5733.2012.09.024

Liu, J. Y., Pan, C. J., and Lee, C. C. (2002). VHF radar and MF/HF dynasonde observations during polar mesosphere summer echoes conditions at EISCAT. Earth Planets Space, 54(6), 691-698.

https://doi.org/10.1186/BF03351720

Mahmoudian, A., Senior, A., Scales, W. A., Kosch, M. J., and Rietveld, M. T. (2018). Dusty space plasma diagnosis using the behavior of polar mesospheric summer echoes during electron precipitation events. J. Geophys. Res., 123(9), 7697-7709. https://doi.org/10.1029/2018JA025395

Mann, I., Häggström, I., Tjulin, A., Rostami, S., Anyairo, C. C., and Dalin, P. (2016). First wind shear observation in PMSE with the tristatic EISCAT VHF radar. J. Geophys. Res., 121(11), 11271-11281. https://doi.org/10.1002/2016JA023080

Morris, R. J., Murphy, D. J., Klekociuk, A. R., and Holdsworth, D. A. (2007). First complete season of PMSE observations above Davis, Antarctica, and their relation to winds and temperatures. Geophys. Res. Lett., 34(5), L05805. https://doi.org/10.1029/2006GL028641

Ogawa, T., Nishitani, N., Sato, N., Yamagishi, H., and Yukimatu, A. S. (2002). Upper mesosphere summer echoes detected with the Antarctic Syowa HF radar. Geophys. Res. Lett., 29(7), 1157. https://doi.org/10.1029/2001GL014094

Ogawa, T., Arnold, N. F., Kirkwood, S., Nishitani, N., and Lester, M. (2003). Finland $\mathrm{HF}$ and Esrange MST radar observations of polar mesosphere summer echoes. Ann. Geophys, 21(4), 1047-1055. https://doi.org/10.5194/angeo-211047-2003

Ogawa, T., Kawamura, S., and Murayama, Y. (2011). Mesosphere summer echoes observed with VHF and MF radars at Wakkanai, Japan $\left(45.4^{\circ} \mathrm{N}\right)$. Atmos. SolarTerr. Phys., 73(14-15), 2132-2141. https://doi.org/10.1016/j.jastp.2010.12.016

Ogawa, T., Nishitani, N., Kawamura, S., and Murayama, Y. (2013). Mesosphere summer echoes observed with the SuperDARN Hokkaido HF radar at Rikubetsu, Japan (43.5N). Earth Planets Space, 65(12), 1593-1597. https://doi.org/10.5047/eps.2013.07.009

Rauf, A., Li, H. L., Ullah, S., Meng, L., Wang, B., and Wang, M. Y. (2018). Statistical study about the influence of particle precipitation on mesosphere summer echoes in polar latitudes during July 2013. Earth Planets Space, 70(1), 108. https://doi.org/10.1186/s40623-018-0885-6

Rauf, A., Li, H. L., Ullah, S, Wang, M. Y., and Meng, L. (2019). Investigation of PMSE echoes characteristics using the discontinuous EISCAT UHF observation and its relation with space environment. Adv. Polar Sci., 30(2), 132-138. https://doi.org/10.13679/j.advps.2018.0041

Rietveld, M. T., Wright, J. W., Zabotin, N., and Pitteway, M. L. V. (2008). The Troms $\varnothing$ dynasonde. Polar sci., 2(1), 55-71. https://doi.org/10.1016/j.polar.2008.02.001

Smirnova, M., Belova, E., Kirkwood, S., and Mitchell, N. (2010). Polar mesosphere summer echoes with ESRAD, Kiruna, Sweden: variations and trends over 1997-2008. Atmos. Solar-Terr. Phys., 72(5-6), 435-447. https://doi.org/10.1016/j.jastp.2009.12.014

Yi, W., Xue, X. H., Reid, I. M., Murphy, D. J., Hall, C. M., Tsutsumi, M., Ning, B. Q., Li, G. Z., Vincent, R. A., ... Dou, X. K. (2019). Climatology of the mesopause relative density using a global distribution of meteor radars. Atmos. Chem. Phys., 19(11), 7567-7581. https://doi.org/10.5194/acp-19-7567-2019 